\title{
Brown Marmorated Stink Bug, Halyomorpha halys Ståhl (Insecta: Hemiptera: Pentatomidae) ${ }^{1}$
}

Jamba Gyeltshen, Gary Bernon, and Amanda Hodges²

\section{Introduction}

The brown marmorated stink bug (BMSB), Halyomorpha halys (Ståhl), is a recently introduced pest to the western hemisphere and was first officially reported from Allentown, Pennsylvania in 2001 (Hoebeke and Carter 2003). This stink bug may become a major agricultural pest in North America, similar to the southern green stink bug, Nezara viridula (L.). Both species are polyphagous pests of various crops, but the exact potential impact of BMSB is currently unknown until it is detected in agricultural areas. However, in eastern Asia where the BMSB is native or indigenous, it is a pest on fruit trees and soybeans.

\section{Synonymy}

There is considerable confusion in the genus and a revision is needed; all references to Halyomorpha species in Japan, Korea, and east-China are Halyomorpha halys (Rider et al., in press).

\section{Distribution}

Although the first specimen was positively identified in 2001 (Hoebeke and Carter 2003), there were numerous reports of a nuisance stink bug in Allentown, Pennsylvania, at least several years prior to that date. Interviews with homeowners indicated that there were likely breeding populations in Allentown as early as 1996 (Bernon 2004). Unlike other stink bug species, the BMSB will enter homes and other buildings seeking warm, overwintering sites, and become a nuisance pest. This behavior resulted in many complaints to the Lehigh County Extension in Allentown (Jacobs and Bernhard 2003). By 2001, the stink bug has been found in five counties in eastern Pennsylvania and two counties in New Jersey (Hamilton and Shearer 2002).

BMSB is ideal for a "hitchhiking" type of dispersal, due to its overwintering behavior. In addition, it is a strong flier. Eventually, it will probably spread throughout the United States and southern Canada (Bernon 2004). As of 2005, in addition to the many confirmed reports from Pennsylvania and New Jersey, there are now isolated reports from several eastern states and Oregon

1. This document is EENY-346, one of a series of Featured Creatures from the Entomology and Nematology Department, Florida Cooperative Extension Service, Institute of Food and Agricultural Sciences, University of Florida. Published: April 2005. This document is also available on Featured Creatures Website at http://creatures.ifas.ufl.edu. Please visit the EDIS Website at http://edis.ifas.ufl.edu. 2. Jamba Gyeltshen and Amanda Hodges, Department of Entomology and Nematology, University of Florida; and Gary Bernon, USDA-APHIS.

The Institute of Food and Agricultural Sciences (IFAS) is an Equal Opportunity Institution authorized to provide research, educational information and other services only to individuals and institutions that function with non-discrimination with respect to race, creed, color, religion, age, disability, sex, sexual orientation, marital status, national origin, political opinions or affiliations. U.S. Department of Agriculture, Cooperative Extension Service, University of Florida, IFAS, Florida A. \& M. University Cooperative Extension Program, and Boards of County Commissioners Cooperating. Larry Arrington, Dean 
(LaBonte 2005). Rutgers University will be tracking the expanding distribution while evaluating options for future integrated pest management (IPM)( Nielsen and Hamilton 2005).

\section{Identification}

Typical of other stink bugs, the BMSB has a shield-shaped body and emits a pungent odor when disturbed. With a mottled brown, 12 to $17 \mathrm{~mm}$ long (approximately $1 / 2$ inch) body, it has characteristic alternating dark and light bands across the last two antennal segments that appear as a single white band in both nymphs and adults. This is the most distinguishing characteristic in the field, although it can easily be confused with native brown stink bugs from the genera Brochymena and Euschistus (Hobeke and Carter 2003). If stink bugs are found flying into homes in the fall, they are probably the BMSB and should be reported to the UF/IFAS Cooperative Extension Service or the Florida Department of Agriculture and Consumer Services - Division of Plant Industry. Specimens should be collected for positive identification. Although the brown mottled color is distinctive, there are several native species of brownish stink bugs that will look very similar to the BMSB.

Eggs: The white or pale green barrel-shaped eggs are laid in clusters on the undersides of leaves. Egg masses have about 25 eggs that are only about 1 $\mathrm{mm}$ in diameter but become apparent when nymphs have recently emerged, as they will stay at the egg mass for several days. In Pennsylvania, eggs first appeared in late June, but females continued to lay egg masses until September. Although only one generation was observed, there are likely to be multiple generations as the distribution spreads south (Bernon 2004).

Nymphs: As with all immature stink bugs, the nymphs lack fully developed wings and have been described as tick-like in appearance, ranging in size from $2.4 \mathrm{~mm}$ (1st instar) to $12 \mathrm{~mm}$ (5th instar). Nymphs need to molt, or shed their outer skin (exoskeleton), as they progress through five different stages or nymphal instars. First instars are orange or red in color and remain clustered around the egg mass, sometimes until they molt to the 2 nd instar

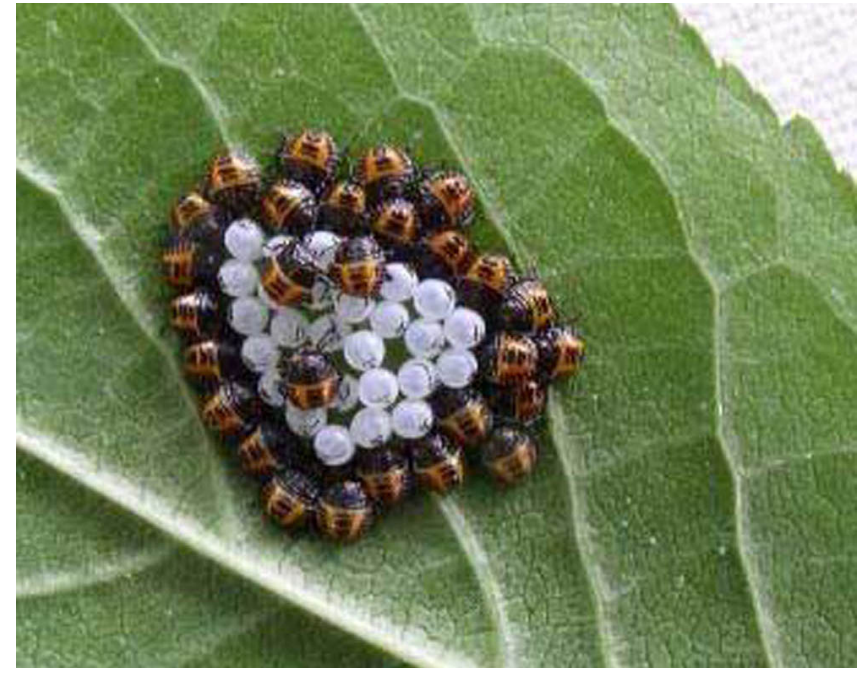

Figure 1. An egg mass of the brown marmorated stink bug, Halyomorpha halys Ståhl, and newly emerged 1st instar nymphs are shown. Credits: Karen Bernhard, Lehigh County Extension, Pennsylvania State University

stage. The 2 nd instar begins to develop an almost black appearance, and subsequent instars (3rd, 4th, and 5th) begin to acquire more of the adult BMSB coloration.

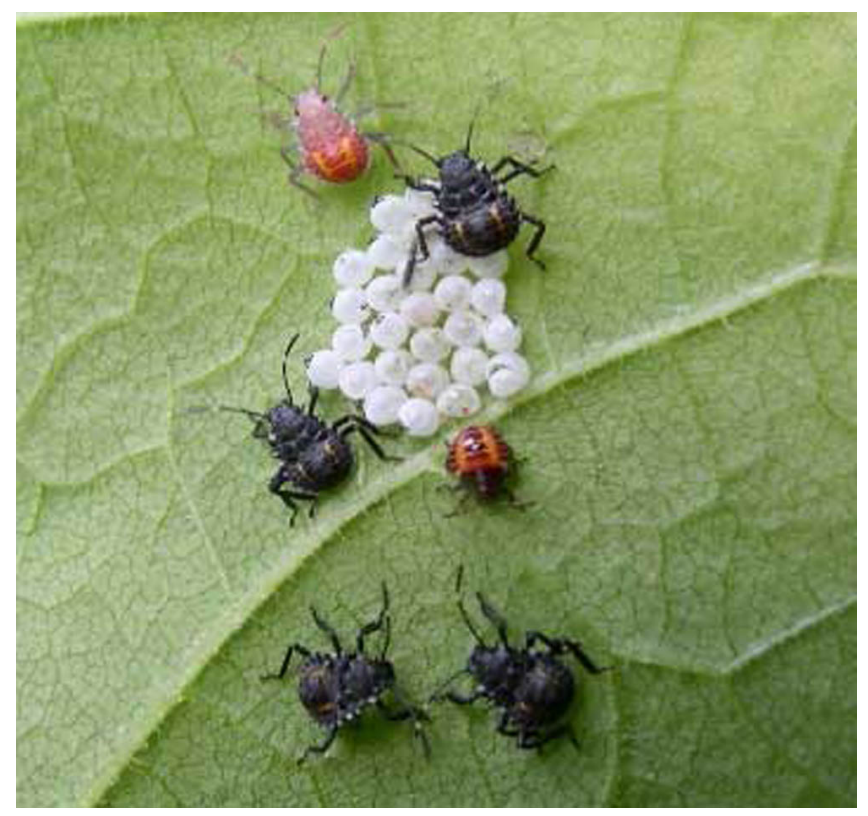

Figure 2. First and 2nd instar nymphs are shown dispersing from an egg mass of the brown marmorated stink bug, Halyomorpha halys Ståhl, in Allentown, Pennsylvania. Credits: Gary Bernon, USDA-APHIS

Adults: Adults are 12 to $17 \mathrm{~mm}$ long (approximately $1 / 2$ inch), and have a mottled appearance. Alternating dark and light bands occur on the last two antennal segment. Additionally, the head and pronotum are covered with patches of coppery or 


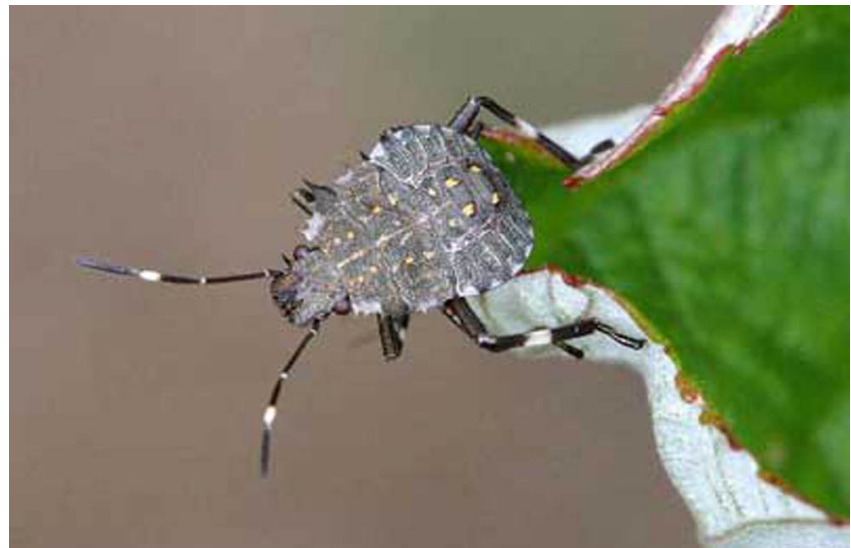

Figure 3. A 2nd instar nymph of the brown marmorated stink bug, Halyomorpha halys Ståhl. The white marking on the antennae is possibly the best field identification characteristic. Credits: Deepak Matadha, Rutgers University

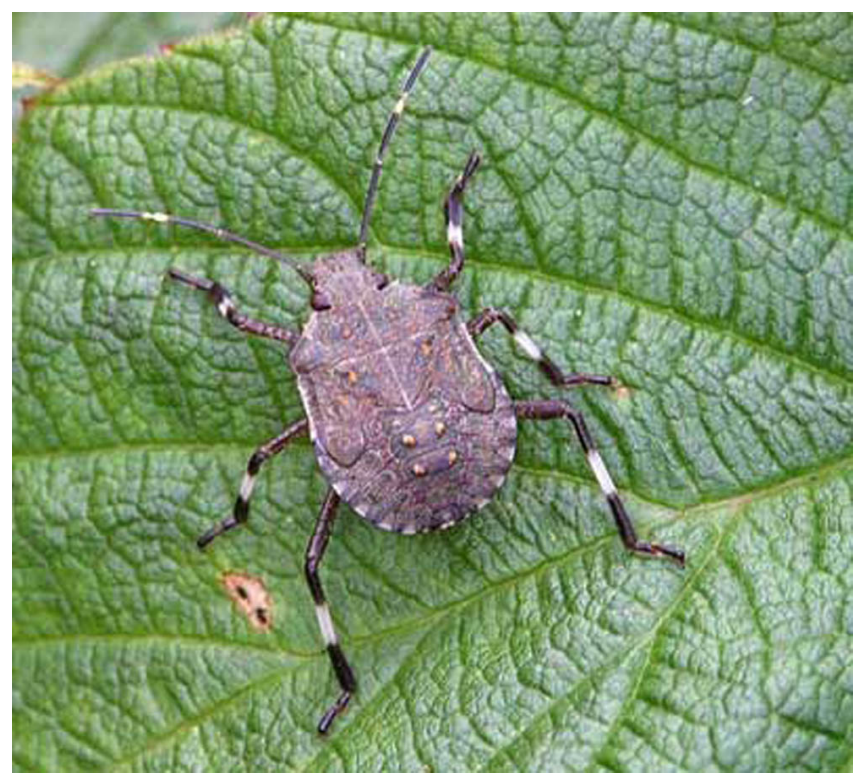

Figure 4. Fifth instar nymph of the brown marmorated stink bug, Halyomorpha halys Ståhl, on raspberry in Allentown, Pennsylvania. Credits: Gary Bernon, USDA-APHIS

bluish metallic-colored punctures and the margins of the pronotum are smooth as compared to the toothed, jagged pronotal margin of Brochymena (Hoebeke 2002). The exposed lateral margins of the abdomen are marked with alternate bands of brown and white. Faint white bands are also evident on the legs.

\section{Life Cycle}

In Pennsylvania, the BMSB has only one generation a year, corresponding to the northern part of its native range. However, in southern China up to

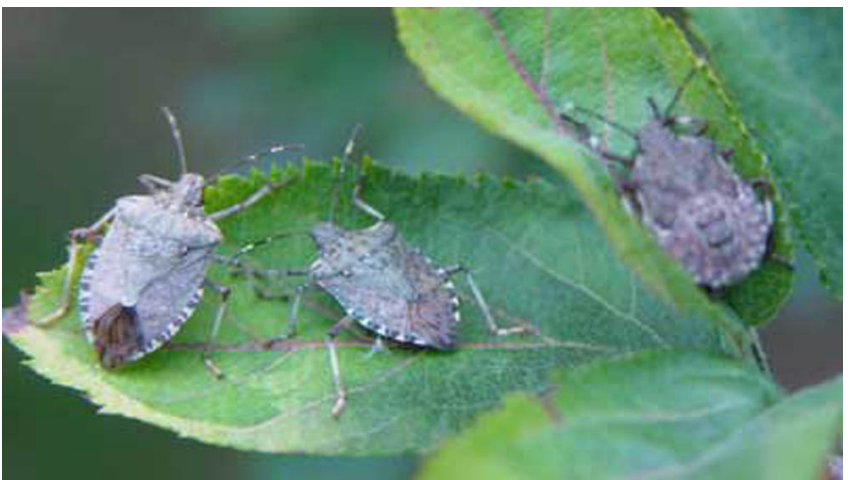

Figure 5. Two adults and one 5th instar nymph of the brown marmorated stink bug, Halyomorpha halys Ståhl, in Allentown, Pennsylvania on crab apple. Credits: Gary Bernon, USDA-APHIS

five generations occur each year, and the same pattern can be expected as the BMSB spreads south (Hoebeke and Carter 2003, Hoffmann 1931). The adults mate in the spring approximately two weeks after emerging from diapause or the resting phase. After a short period, the females begin laying egg masses. Egg masses are laid at approximately weekly intervals, and each female lays as many as 400 eggs in her lifetime. In Pennsylvania, females were observed laying eggs from June to September. Since females continue to lay new egg masses throughout the season, different nymphal stages were often observed on the same host plant.

First instar nymphs emerge four to five days after eggs are laid. Nymphs are solitary feeders, but they occasionally aggregate between overlapping leaves or leaf folds (Bernon 2004). BMSB has five nymphal instars, and each stage lasts approximately one week, depending upon temperature. Laboratory studies indicate that adults are sexually mature two weeks after their final molt (Hoebeke and Carter 2003). Adults are very active and drop from plants or fly when disturbed. Again, the best field characteristic for adults is the white band on the antennae.

\section{Economic Importance and Damage}

BMSB is polyphagous, and is a pest of several important crops in its native range. In Japan it attacks shade and fruit trees, vegetables, and leguminous crops (Hoebeke 2002). In southern China, it feeds on flowers, stems and pods of various legumes, and also on flowers of hibiscus (Hibiscus rosa-sinensis L.), stems of celosia (Celosia argentea $\mathrm{L}$.), fruits of black 


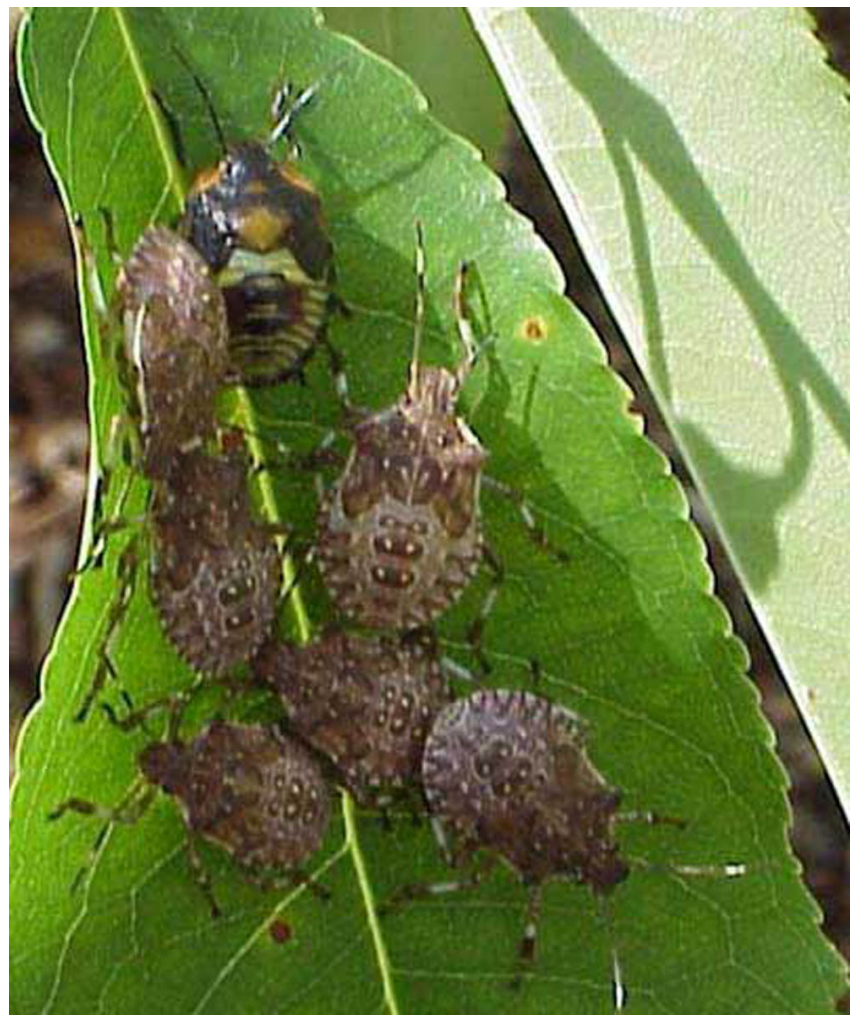

Figure 6. Six 5th instar nymphs of brown marmorated stink bug, Halyomorpha halys Ståhl, with one 5th instar nymph of green stink bug, Acrosternum hilare (Say) in Allentown, Pennsylvania on black cherry. Credits: Gary Bernon, USDA-APHIS

night-shade (Solanum nigrum L.) and malabar/Indian/ceylon spinach (Basella rubra L.). Other host plants of economic importance include Citrus spp., Japanese persimmon (Diospyros kak L.), fig (Ficus), soybean (Glycine max Merrill), apple (Malus domestica L.), mulberry (Morus sp.), the princess tree (Paulownia tomentosa Thunb.), cherry (Prunus avium L.), Japanese apricot (Prunus mume Siebold and Zuccarini), peach (Prunus persica Batsch), and pear (Pyrus pyrifolia Nakai) (Hoebeke 2002, Hoebeke and Carter 2003). Unfortunately, it is difficult to assess the damage caused by one species of stink bug, since several species cause similar damage. A similar situation may occur in the southern U.S., as the BMSB spreads south and overlaps with the distribution of the southern green stink bug (Bernon 2004).

Originally, populations in Pennsylvania were limited to ornamental plants, garden crops, fruit and shade trees in suburban areas and urban landscapes (Bernon et al. 2004). Damage was observed on several ornamentals, including butterfly-bush (Buddleia spp), and the princess tree ( $P$. tomentosa).
Both adults and nymphs fed on the leaves of these two host plants, and leaf damage was very apparent by the end of the season (Bernon 2004). These two ornamentals may attract the stink bug as it spreads to new areas, and homeowners are likely to be the first to see this new pest. Significant damage was also reported on urban peach and pear crops. Following the first official identification of BMSB, Bernon et al. (2004) found BMSB on over 60 host plants.

As the BMSB continues to expand its range, it is likely to invade agricultural areas and may pose a risk to various crops. Similar to other stink bugs, the nymphs and adults have a piercing-sucking type of mouthpart. In order to obtain the nutrients of the liquid part of the fruit, stink bugs use these mouthparts in a straw-like fashion by piercing the fruit. Small necrotic spots on fruit and leaf surfaces often result from feeding damage, and it may be compounded by secondary infections and scarring as the fruit matures. In particular, affected apples often exhibit pitting and discoloration symptoms and peaches frequently display a characteristic distortion referred to as "catfacing" (Hamilton and Shearer 2003). Even if a fruit such as a peach is still edible, it may not be suitable for market. Similar damage to other crops, such as soybeans, is more likely to occur in the southern US. The BMSB is also known to vector or spread a plant disease that is important to at least one tree crop in Asia (Hiruki 1999). Because the BMSB is polyphagous, or feeding on a wide range of host plants, almost any crop with fruit may be at risk.

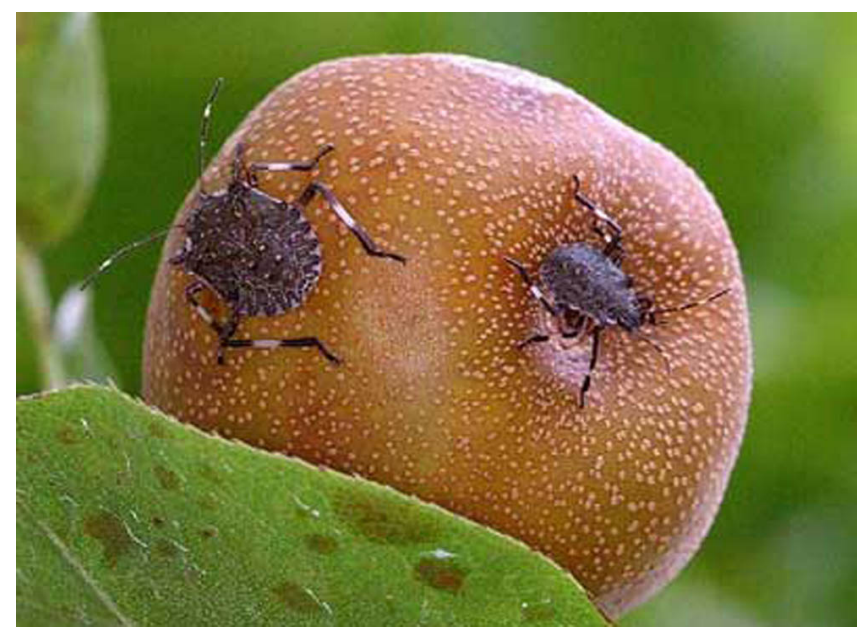

Figure 7. Early and late instar nymphs of the brown marmorated stink bug, Halyomorpha halys Ståhl, feeding on Asian pear in Allentown, Pennsylvania. Credits: Deepak Matadha, Rutgers University 


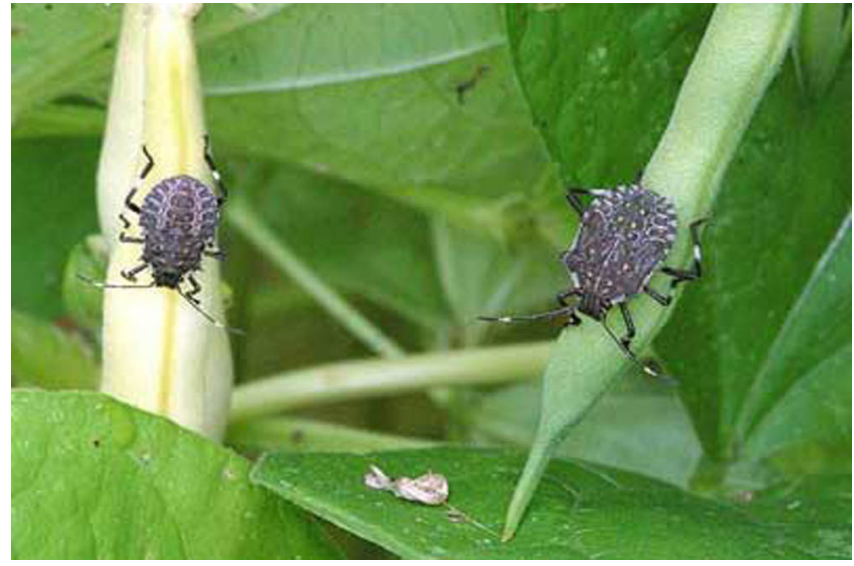

Figure 8. Nymphs of the brown marmorated stink bug, Halyomorpha halys Ståhl, feeding on green beans in Allentown, Pennsylvania. Credits: Deepak Matadha, Rutgers University

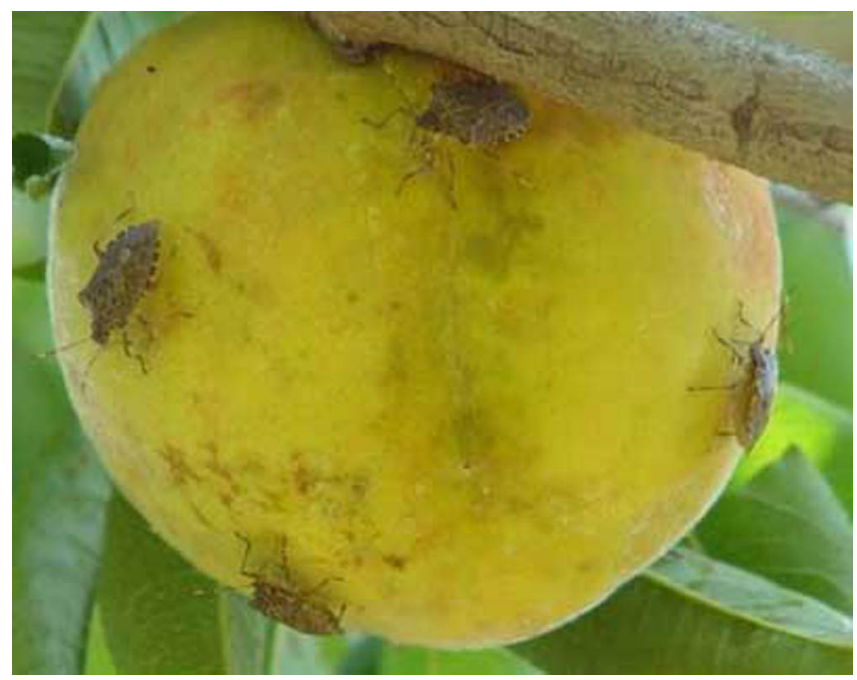

Figure 9. Adults of the brown marmorated stink bug, Halyomorpha halys Ståhl feeding on peach in Allentown, Pennsylvania. Characteristic damage is evident. Credits: Gary Bernon, USDA-APHIS

\section{Nuisance Pest Status}

Late in the season, adults will enter homes and other buildings when seeking sheltered sites to overwinter, or diapause. During the several weeks of peak flight, many insects can enter homes through any small opening, mostly around windows. In Japan, the BMSB is a well-known nuisance pest for this reason, and the same situation is now common in Allentown, Pennsylvania in late September and early October. This nuisance behavior resulted in many complaints to the Lehigh County (Allentown) Cooperative Extension Service, and ultimately resulted in the identification of this new invasive pest. As the insect spreads to new areas, this

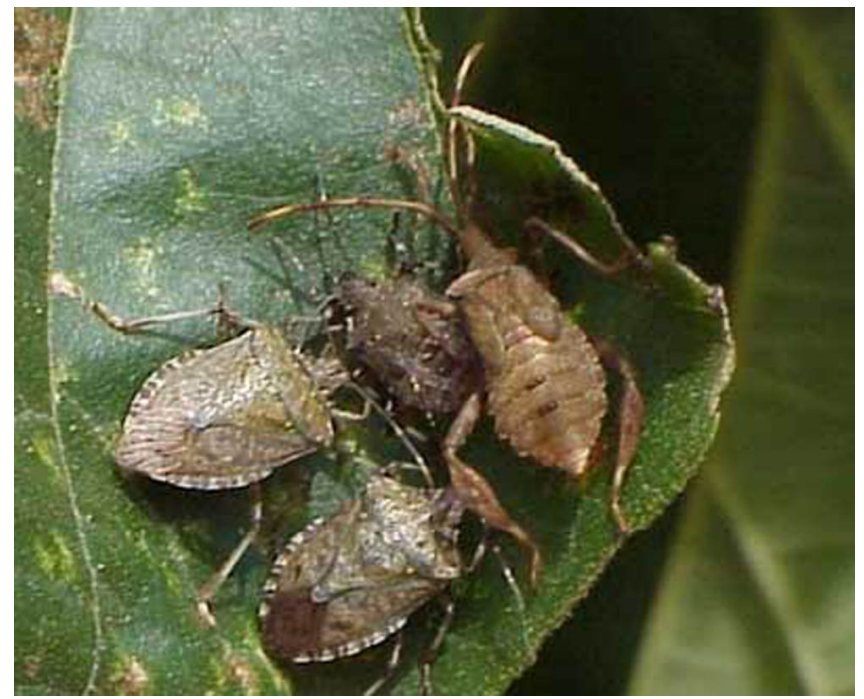

Figure 10. Two adults and a nymph of the brown marmorated stink bug, Halyomorpha halys Ståhl, feeding on one of its main hosts, princess tree in Allentown, Pennsylvania. Characteristic feeding damage of the brown marmorated stink bug is also evident. Late instar nymphs of leaf-footed bugs (Hemiptera: Coreidae) are often mistakenly submitted as brown marmorated stink bug samples. The Coreidae pictured is probably the western conifer seed bug, Leptoglossus occidentalis Heidemann. Credits: Gary Bernon, USDA-APHIS

aggregation behavior will probably again attract attention and ironically assist in monitoring its distribution. The nuisance aspect is a major concern in suburban areas and may distract from the potential future agricultural risks (Bernon 2004).

\section{Management}

Indoor nuisance pest problems. Mechanical exclusion and chemical control have been suggested for preventing nuisance, overwintering pest problems in residential homes and commercial businesses (Jacobs and Bernhard 2003). BMSB can be mechanically excluded by sealing cracks and other building openings with quality silicone or silicone latex caulk. Damaged screens on doors or windows should be repaired or replaced. Some synthetic pyrethroid insecticides available to commercial pesticide applicators may be applied to the exterior of the home just prior to fall aggregations, but the effectiveness of these chemcial sprays is only temporary. Sunlight will degrade synthetic pyrethroid insecticides within a few days to a week of the application. 
Urban pest management. Occasionally stink bugs were observed to damage ornamentals in Allentown, including butterfly bush, Paulownia shade trees and crabapples. Although insecticides were used, plant damage was minimal and most control efforts were focused on suppression of nuisance population. Despite insecticidal treatments, some damage was still observed on backyard fruit trees. This documented damage to agriculturally important crops suggests that there will be a need for IPM when populations reach agricultural areas (Bernon 2004).

Future IPM. As of 2005, management planning was in the formative stages, primarily because the pest established first in landscaped habitats, and not agricultural areas. Results from a one-year USDA study indicated that the BMSB is a risk to agriculture, and documented that several native parasites and predators had been able to attack this new host (Bernon 2004). The USDA Agricultural Research Service is proposing to study biological control as an optionfor IPM programs (Fuester, personal communication). The Rutgers University Cooperative Extension Service and the New Jersey Department of Agriculture are currently combining efforts to evaluate survey and research needs while at the same time studying the biology of this emerging pest in the laboratory (Nielsen and Hamilton 2005). Damage thresholds will need to be determined, and although existing management strategies may apply, additional research will be needed.

\section{Selected References}

Bernon G. (2004). Biology of Halyomorpha halys, the brown marmorated sink bug (BMSB). Final Report - USDA APHIS CPHST 2004 (one year project). http://www.cphst.org/docs/

BernonfinalreportT3P01.pdf (1 April 2005).

Bernon G, Bernhard KM, Hoebeke ER, Carter ME, Beanland LA. (2004). Halyomorpha halys, (Heteroptera: Pentatomidae), the brown marmorated stink bug: are trees the primary or reservoir hosts for this new invasive pest? http://www.cphst.org/docs/ Bernon-presentation04.ppt (29 December 2004).

Bernon G, Bernhard KM, Hoebeke ER, Carter ME. (2003). Halyomorpha halys, (Heteroptera: Pentatomidae), New Nuisance Pest: and Future

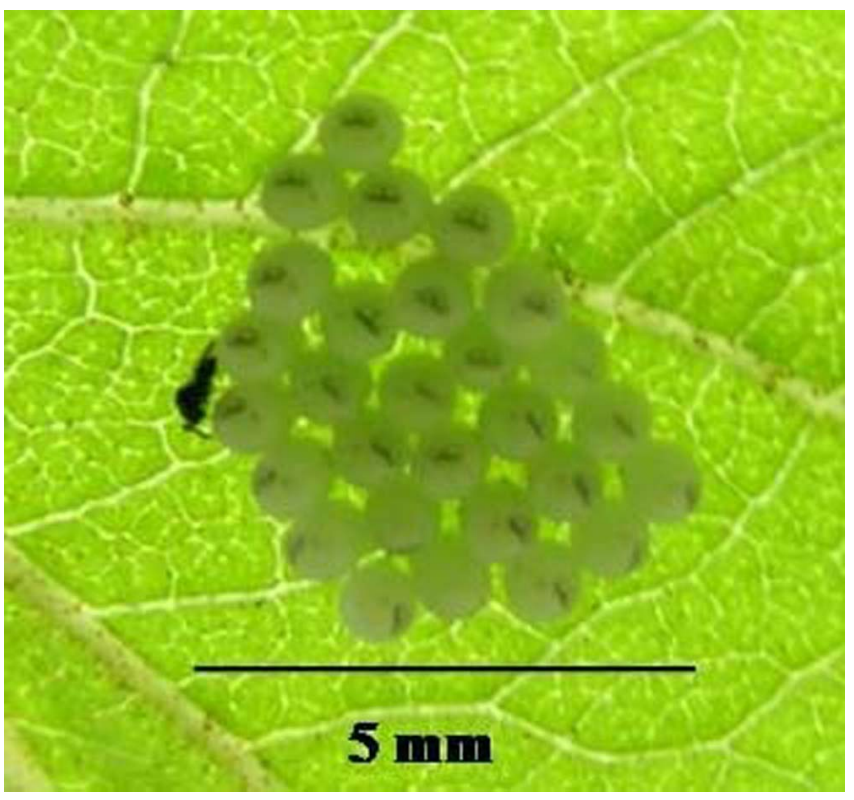

Figure 11. Telenomus podisi (Hymenoptera: Scelionidae), a generalist stink bug parasitoid that was recently recorded for the brown marmorated stink bug, Halyomorpha halys Ståhl. The host plant in this photo is a princess tree, Paulownia tomentosa, in Allentown, Pennsylvania. Credits: Gary Bernon, USDA-APHIS

Agricultural Problem? http://www.cphst.org/ download.cfm?file=ESA2003a.ppt (29 December 2004).

Hamilton GC, Shearer PW. (2003). Brown marmorated stink bug - a new exotic insect in New Jersey. FS002. Rutgers Cooperative Research \& Extension. http://www.rce.rutgers.edu/pubs/pdfs /fs002.pdf (1 January 2005).

Hoffmann WE. 1931. A pentatomid pest of growing beans in south China. Peking Natural History Bulletin 5(3): 25-26.

Hoebeke ER. (2002). Brown marmorated stink bug, Halyomorpha halys (Stal) Heteroptera: Pentatomidae. Entomology Circular No. 204. Pennsylvania Department of Agriculture. http://www.agriculture.state.pa.us/plantindustry/lib/ plantindustry/vol28_11.pdf (20 January 2005).

Hoebeke ER. Carter ME. 2003. Halyomorpha halys (Stal) (Heteroptera: Pentatomidae): a polyphagous plant pest from Asia newly detected in North America. Proceedings of the Entomological Society of Washington, January 2003. v. 105. pp. 225-237. 
Jacobs SB, Bernhard KM. (2003). Brown

marmorated stink bug Halyomorpha halys. NP-15.

The Pennsylvania State University Entomology

Notes. http://www.ento.psu.edu/extension/factsheets

/pdfs/brMarmoratedStinkBug.pdf (22 March 2005).

LaBonte J. (2005). Brown marmorated stink bug. Oregon Department of Agriculture Pest Alert. http://egov.oregon.gov/ODA/PLANT/docs/pdf/ ippm_halyomorpha.pdf (22 March 2005).

Nielsen A, Hamilton G. (2005). Monitoring for the brown marmorated stink bug. Rutgers Cooperative Research \& Extension. http://www. rce.rutgers.edu/stinkbug/ (22 March 2005).

Rider DA, et al. In press. Checklist and nomenclature notes on the Chinese Pentatomidae (Heteroptera). II. Pentatomidae. Zoosystematica Rossica. 